\title{
Vaccine-Derived Polioviruses and Children with Primary Immunodeficiency, Iran, 1995-2014
}

\author{
Mohammadreza Shaghaghi, ${ }^{1}$ Shohreh Shahmahmoodi, ${ }^{1}$ Hassan Abolhassani, Saeed Soleyman-jahi, \\ Leila Parvaneh, Sussan Mahmoudi, Zahra Chavoshzadeh, Reza Yazdani, Seyed Mohsen Zahraei, \\ Mohsen Ebrahimi, Mohammad H. Eslamian, Hamideh Tabatabaie, Maryam Yousefi, \\ Yaghoob M. Kandelousi, Aliasghar Oujaghlou, Nima Rezaei, Asghar Aghamohammadi
}

Widespread use of oral poliovirus vaccine has led to an $\approx 99.9 \%$ decrease in global incidence of poliomyelitis (from $\approx 350,000$ cases in 1988 to 74 cases in 2015) and eradication of wild-type poliovirus serotypes 2 and 3 . However, patients with primary immunodeficiency might shed vaccinederived polioviruses (VDPVs) for an extended period, which could pose a major threat to polio eradication programs. Since 1995, sixteen VDPV populations have been isolated from 14 patients with immunodeficiency in Iran. For these patients, vaccine-associated paralysis, mostly in $>1$ extremity, was the first manifestation of primary immunodeficiency. Seven patients with humoral immunodeficiency cleared VDPV infection more frequently than did 6 patients with combined immunodeficiencies. Our results raise questions about manifestations of VDPVs in immunodeficient patients and the role of cellular immunity against enterovirus infections. On the basis of an association between VDPVs and immunodeficiency, we advocate screening of patients with primary immunodeficiency for shedding of polioviruses.

$\mathrm{I}_{\mathrm{o}}^{\mathrm{n}}$ n 1988, the World Health Assembly of the World Health Organization resolved to eradicate poliomyelitis through

Author affiliations: Tehran University of Medical Sciences, Tehran, Iran (M. Shaghaghi, S. Shahmahmoodi, H. Abolhassani,

S. Soleyman-jahi, L. Parvaneh, M. Ebrahimi, M.H. Eslamian,

N. Rezaei, A. Aghamohammadi); Universal Scientific Education and Research Network, Tehran (M. Shaghaghi, H. Abolhassani, S. Soleyman-jahi, R. Yazdani, N. Rezaei, A. Aghamohammadi); Research Center for Immunodeficiences, Tehran (M. Shaghaghi, H. Abolhassani, N. Rezaei, A. Aghamohammadi); Tehran University of Medical Sciences School of Public Health, Tehran (S. Shahmahmoodi, H. Tabatabaie, M. Yousefi, Y.M. Kandelousi, A. Oujaghlou); Ministry of Health and Medical Education, Tehran (S. Mahmoudi, S.M. Zahraei); Shaheed Beheshti Medical University, Tehran (Z. Chavoshzadeh); Isfahan University of Medical Sciences School of Medicine, Isfahan, Iran (R. Yazdani); Children's Medical Center, Tehran (M. Ebrahimi, M.H. Eslamian)

DOI: http://dx.doi.org/10.3201/eid2210.151071 the introduction of vaccination on a worldwide scale as the main tool against transmission of poliovirus $(1,2)$. Endemic poliomyelitis has been eliminated from most parts of the world by vaccination with live attenuated oral poliovirus vaccine (OPV) and inactivated poliovirus vaccine (IPV) (3). The annual incidence of wild-type poliomyelitis has decreased by $\approx 99.9 \%$ from $\approx 350,000$ cases in 1988 to 74 cases in 2015, and only 2 countries, Afghanistan and Pakistan, still have transmission of wild-type poliovirus (2).

As the polio eradication program is proceeding, emergence of vaccine-derived polioviruses (VDPVs) could be a major threat to the success of current strategies. VDPVs are variants of 3 OPV serotypes (PV1, PV2, and PV3), which during prolonged intestinal replication show $>1 \%$ (PV1 and PV3) or $>0.6 \%$ (PV2) nucleotide divergence in the viral protein 1 (VP1) coding region (4). Only a small number of genetic mutations are responsible for reduced neurovirulence in OPV strains (5). Revertant vaccine viruses with increased neuropathogenicity might cause vaccine-associated paralytic poliomyelitis (VAPP) in OPV recipients or unimmunized contacts. VAPP is the most common adverse event after OPV administration (6). Because of impaired systemic or mucosal immunity, patients with primary immunodeficiencies are at a markedly increased risk for VAPP (6). In addition, patients with primary immunodeficiencies might shed VDPVs (immunodeficiency-associated VDPV [iVDPV]) in stool samples for an extended period after exposure to OPV strains (7). Vaccine-derived polioviruses might also circulate in the community (circulating VDPV) through person-to-person transmission and occasionally cause symptomatic infections in immunodeficient or healthy persons $(6)$.

In recent years, several studies have focused on environmental detection of VDPVs and their community circulation. Some studies investigated VDPVs in immunodeficient persons, which lead to identification of $\approx 100$ cases

${ }^{1}$ These authors contributed equally to this article. 
of infection with iVDPV worldwide to date $(1,8)$. We have previously reported several cases of infection with iVDPV in Iran and emphasized the need for surveillance of iVDPV (9-13). We report newly identified persons who shed iVD$\mathrm{PV}$ and review additional characteristics of cases reported.

\section{Objectives}

In this study, we report clinical characteristics of 14 VAPP patients and virologic properties of their iVDPV isolates. All patients were identified in Iran during 1995-2014. We sought to determine relationships between clinical features of underlying immunodeficiency disorders, VDPV manifestations, and patient outcomes.

\section{Study Design}

Patients in Iran with acute flaccid paralysis (AFP) were tested for shedding of polioviruses in stool specimens during national AFP surveillance up to the end of 2014. Stool specimens were collected at the earliest convenience within 48 hours after onset of paralysis. Fecal shedding of vaccine virus strains was simultaneously investigated in close contacts of patients.

Specimens were processed at the Iranian National Polio Laboratory (Tehran, Iran). Virus isolation, serotype identification, and intratypic differentiation were performed by using the World Health Organization protocol for poliovirus detection in stool specimens (14). Screening for VDPV shedding was performed by using an ELISA, reverse transcription PCR, or real-time reverse transcription PCR. Genome sequencing of isolates was conducted at the Centers for Disease Control and Prevention (CDC; Atlanta, GA, USA). The VP1 divergence rate was defined as the value (percentage) of VP1 divergence divided by years of virus replication from the original Sabin strain. To calculate this rate, we considered the interval between first OPV administration and date of the most recent isolation of iVDPVs as the duration of virus replication.

Clinical and laboratory data were obtained from the national primary immunodeficiency registry and AFP surveillance database $(15,16)$. Patients with undetermined immune status were analyzed to determine serum levels of immunoglobulins and absolute leukocyte and different lymphocyte subpopulation counts. Immunity disorders were defined according to the Expert Committee of the International Union of Immunological Societies (17). Agammaglobulinemia, hypogammaglobulinemia, and mu heavy chain disease were considered humoral immunodeficiencies. Combined immunodeficiency (CID) included severe combined immunodeficiency, major histocompatibility complex class 2 deficiency, and Nijmegen breakage syndrome.

We evaluated patients by monthly collection of stool specimens and analysis until patients cleared their infections or died of any cause. Patients were classified into separate subgroups according to types of immunodeficiency (humoral or combined) and whether virus shedding in stool specimens was cleared before death. Patients were considered as having cleared an IVDPV infection if 2 consecutive stool specimens were negative for iVDPVs.

\section{Statistical Analyses}

Continuous variables are reported as means $\pm \mathrm{SD}$. We used the Shapiro-Wilk normality test to assess distribution of study parameters. We used the $\chi^{2}$ test to analyze relationships between categorical parameters, the Mann-Whitney $\mathrm{U}$ test to compare duration of shedding and VP1 divergence rate between different subgroups, and an independent $t$-test to compare age of onset of VAPP and absolute VP1 divergence. $\mathrm{p}$ values $<0.05$ were considered statistically significant.

\section{Results}

\section{Patients and Manifestations}

During 1995-2014, a total of 14 patients (12 boys and 2 girls) infected with iVDPV were identified in Iran. Mean \pm SD age at onset of VAPP was 12.4 \pm 5.8 months for all patients. Mean \pm SD age at onset of VAPP was $14.1 \pm 4.1$ months for patients with humoral immunodeficiency and $10.2 \pm 7.5$ months for patients with combined immunodeficiency. However, this difference was not significant $(\mathrm{p}=$ 0.26 ). Eight patients had paresis in $>1$ extremity, and 4 patients had monoparesis. Data were discordant for 2 patients for defining monoparesis or polyparesis.

We analyzed the patients for a mean duration of 18 months; by the end of follow-up, $9(64.3 \%)$ patients had died. As expected, patients with humoral immunodeficiency disorders survived longer than patients with CID $(p<0.05)$. For 5 patients who were alive at the last followup (March 2015), mean \pm SD age was $4.2 \pm 3.3$ years. Detailed clinical characteristics for all patients are shown in Table 1, and virologic properties of iVDPVs are shown in Table 2.

\section{Types of Primary Immunodeficiencies}

Except for 1 patient who died before immunologic studies were completed (patient 12), all patients with VDPV shedding had primary immunodeficiency. Seven patients had humoral immunodeficiencies and 6 patients had CIDs (Table 3). Further investigations and genetic analysis were performed for 8 patients to identify the genes responsible for immunodeficiency. Four patients had mutations in the Bruton tyrosine kinase gene, and a final diagnosis of $\mathrm{X}$-linked agammaglobulinemia was established. Low expression of human leukocyte antigen DR on B lymphocytes indicated major histocompatibility complex class 2 
Table 1. Clinical characteristics for 14 patients infected with iVDPV, Iran, 1995-2014*

\begin{tabular}{|c|c|c|c|c|c|}
\hline $\begin{array}{l}\text { Patient } \\
\text { no. }\end{array}$ & $\begin{array}{c}\text { Age, mo, at } \\
\text { VAPP onset/sex }\end{array}$ & $\begin{array}{l}\text { No. } \\
\text { doses } \\
\text { OPV }\end{array}$ & $\begin{array}{l}\text { Duration, mo, from } \\
\text { last OPV dose to } \\
\text { VAPP onset }\end{array}$ & $\begin{array}{l}\text { Duration from } \\
\text { VAPP onset to } \\
\text { death } \dagger\end{array}$ & Site of paralysis \\
\hline 1 & $17.4 / \mathrm{F}$ & 0 & NA & $8 \mathrm{~d}$ & NA \\
\hline 2 & 7.5/M & 4 & 1.1 & $4 \mathrm{mo}$ & Left leg, right leg, right arm, respiratory muscles \\
\hline 3 & 10.6/M & 4 & 3.3 & $1 \mathrm{mo}$ & Left leg, right leg, right arm \\
\hline 4 & 15.1/M & 4 & 9 & $11 \mathrm{mo}$ & Left leg, right leg \\
\hline 5 & $5.3 / F$ & 2 & 3.2 & $<1 \mathrm{mo}$ & Left leg, right leg \\
\hline 6 & $20.2 / \mathrm{M}$ & 4 & 1.1 & Alive & Right leg \\
\hline 7 & $6.2 / \mathrm{M}$ & 3 & 2 & $28 \mathrm{mo}$ & Right leg \\
\hline 8 & $15.7 / \mathrm{M}$ & 4 & 9.2 & Alive & Left leg, right leg, left arm \\
\hline 9 & 25.2/M & 4 & 6.7 & $<1 \mathrm{mo}$ & Left leg \\
\hline 10 & 6.6/M & 1 & 6.6 & $2 \mathrm{mo}$ & Left leg, right leg \\
\hline 11 & 11.4/M & 3 & 5.3 & Alive & Left leg \\
\hline 12 & 13.1/M & 2 & 7 & $18 \mathrm{~d}$ & Not available \\
\hline 13 & $10.0 / \mathrm{M}$ & 4 & 3 & Alive & Left leg, right leg, left arm \\
\hline 14 & 9.0/M & 4 & 2.8 & Alive & Left leg, right leg \\
\hline
\end{tabular}

deficiency in patient 2 (12). Patient 3 had severe combined immunodeficiency caused by a mutation in recombination activating gene 2 (R229W) (N. Parvaneh, unpub. data). Mutations in Nijmegen breakage syndrome 1 confirmed a diagnosis of Nijmegen breakage syndrome in patient 7 , and mu heavy chain genes confirmed mu heavy chain disease in patient 11 (H. Abolhassani, unpub. data).

\section{Temporality of VAPP with Diagnosis of Primary Immunodeficiency}

Primary immunodeficiencies in patients were detected mostly after onset of paralysis (11 of 14 patients). Only 3 patients had been given a diagnosis of primary immunodeficiency before onset of VAPP. Patient 1 was screened and given a diagnosis of primary immunodeficiency at birth. Patients 9 and 10 received Mycobacterium bovis BCG vaccine and a first dose of OPV at birth. These 2 patients had multiple BCG-adenitis and respiratory infections at 10 months and 4 months of age, respectively, which led to a diagnosis of primary immunodeficiency. Despite initiation of immunoglobulin replacement, they subsequently had VAPP.

\section{VDPV Characteristics in Primary Immunodeficiency Patients}

Sixteen iVDPV populations were isolated from the 14 patients; 2 patients were simultaneously shedding iVDPV types 1 and 2 . Twelve of 16 viruses isolated were serotype 2 , three were serotype 1 , and 1 was serotype 3 (Table 2). Overall mean \pm SD VP1 divergence was $1.88 \%$ $\pm 0.79 \%$. No differences in values for VP1 divergence were observed between the 2 subgroups of humoral immunodeficiency and combined immunodeficiency patients $(\mathrm{p}=0.58)$. This divergence was also comparable in both subgroups of patients who stopped shedding virus or continued to shed virus $(p=0.75)$.
The mean \pm SD VP1 divergence rate was $1.8 \% \pm 1.1 \%$ (range $0.6 \%-4.3 \%$ ) per year. Similar to absolute VP1 divergence, the VP1 divergence rate was comparable between 2 subgroups of primary immunodeficiency patients $(\mathrm{p}=0.61)$.

\section{Shedding Duration and Clearing Infection in Primary Immunodeficiency Categories}

Duration of iVDPV isolation for the patients ranged from 3 days to 15 months (median 1 month). Seven patients stopped shedding iVDPV. Seven other patients shed iVDPVs in their last stool specimen before death. If we excluded patient 12 , who did not have a definite primary immunodeficiency category, $6(85.7 \%)$ of 7 patients with predominantly humoral immunodeficiencies stopped shedding VDPV, but only $1(16.7 \%)$ of 6 CID patients cleared the infection before death. This association observed between type of primary immunodeficiency and rate of clearing VDPV infection was statistically significant $(p=0.013)$. Patients with humoral immunodeficiencies cleared VDPV infection more frequently than CID patients (Table 2).

Duration of shedding after VAPP onset was similar in both subgroups of patients with humoral immunodeficiency and combined immunodeficiency $(p=0.66)$. Analysis also showed a trend of longer shedding duration in patients who stopped shedding iVDPV than in patients who shed the virus until death $(\mathrm{p}=0.07)$.

\section{Discussion}

We analyzed 14 iVDPV patients identified in Iran during 1995-2014. Detailed characteristics of patients 1-7 have been described (9-13); among these patients, only patient 6 is alive, and this patient has residual paresis. Patient 7, who had AFP at 6 months of age, continued shedding iVDPV2 
for 2 months after the most recent published data and then stopped shedding virus. He died at 34 months of age from pneumonia. Among the 7 newly identified case-patients, patient 12 died before he underwent specific immunologic investigations. This patient had a history of recurrent infections, and sequencing data showed quasispecies of VDPV2 from multiple lineages, which suggested immunodeficiency for this patient. This patient was identified as an iVDPV patient in CDC annual reports (18).

Serotype 2 iVDPV has been the most prevalent serotype detected in immunodeficient patients $(64 \%)$, followed by serotypes $1(21 \%)$ and $3(15 \%)(18)$; our series showed similar findings. We analyzed 2 patients who were simultaneously shedding serotypes 1 and 2 iVDPVs. Concurrent infection with $>1$ VDPV serotype has been documented in 3 other patients from China and the United States $(4,6,19)$. Paralysis in poliomyelitis is usually asymmetric $(6,20)$. In contrast, most of our iVAPP patients had bilateral flaccid paresis. Further studies are required to differentiate manifestations of VDPV infection in primary immunodeficiency patients with poliomyelitis caused by wild-type poliovirus.

Patient 1 received only IPV; however, all his contacts had received OPV as routine national vaccination in Iran. Subsequently, he had VAPP and died of an unknown etiology. All other patients in our study had severe complications of live vaccines (BCG and OPV) given at birth. These complications were the earliest manifestations of primary immunodeficiencies in these patients, which further aggravated their course of disease. Use of screening programs to detect immunodeficiencies at birth could prevent administration of live vaccines to primary immunodeficiency patients and their contacts and minimize the burden of adverse complications.
We observed an association between type of primary immunodeficiency and frequency of clearing iVDPV infection; patients with humoral immunodeficiency cleared VDPV infection more frequently than CID patients. Patients with CID have more severe complications and shorter survival times than patients with humoral immunodeficiency $(16,21)$. This finding could limit the ability of CID patients to clear infections by use of proper immunoglobulin therapy before death. Although this finding might be an explanation for lower rate of infection clearance in CID patients, comparable durations of virus shedding between 2 subgroups of primary immunodeficiency patients do not support this hypothesis and imply a probable contribution of other mechanisms to this observation.

Another explanation for the relationship observed in our study between type of primary immunodeficiency and rate of clearing iVDPV infection might be differences in inherent capacity of these immunodeficiency disorders to respond to polioviruses or other enterovirus infections. To our knowledge, enteral mucosal immunity against enteroviruses is a prominently antibody-mediated mechanism, and patients with major B-cell dysfunction are at increased risk for poliomyelitis $(6,22)$. Nevertheless, our observations suggest other major contributions of cellular immunity to clearance of poliovirus infections. The index case-patient for an outbreak of poliovirus infection in Minnesota, USA, in 2005 had been given a diagnosis of severe combined immunodeficiency. She continued to shed iVDPVs while receiving immunoglobulin therapy for several months and finally stopped shedding virus after a second bone marrow transplant (23).

Similarly, regular intravenous immunoglobulin (IVIg) administration could not protect patients 9 and 10 in our study from VAPP, and neither patient cleared the infection.

\begin{tabular}{|c|c|c|c|c|c|c|c|}
\hline $\begin{array}{l}\text { Patient } \\
\text { no. }\end{array}$ & $\begin{array}{l}\text { Report } \\
\text { year }\end{array}$ & $\begin{array}{l}\text { Age, mo, at } \\
\text { VAPP onset }\end{array}$ & $\begin{array}{l}\text { Virus shedding duration } \\
\text { from VAPP onset }\end{array}$ & $\begin{array}{l}\text { iVDPV } \\
\text { serotype }\end{array}$ & $\begin{array}{c}\text { VP1 nt } \\
\text { divergence, \%† }\end{array}$ & $\begin{array}{l}\text { Cleared } \\
\text { infection }\end{array}$ & No. contacts $\ddagger$ \\
\hline 1 & 1995 & 17.4 & $8 d$ & 2 & 2.2 & No & 0 \\
\hline 2 & 2005 & 7.5 & $3 \mathrm{mo}$ & 2 & 1.5 & No & 6 (all negative) \\
\hline 3 & 2006 & 10.6 & $2 w k$ & 2 & 1.7 & No & 8 (all negative) \\
\hline 4 & 2006 & 15.1 & $5 \mathrm{mo}$ & 3 & 2 & Yes & 7 (all negative) \\
\hline 5 & 2007 & 5.3 & $5 d$ & 2 & 2 & No & 8 (all negative) \\
\hline 5 & 2007 & 5.3 & $5 d$ & 1 & 1.7 & No & 8 (all negative) \\
\hline 6 & 2007 & 20.2 & $3 d$ & 2 & 1.2 & Yes & 5 (all negative) \\
\hline 7 & 2011 & 6.2 & $15 \mathrm{mo}$ & 2 & 2 & Yes & 22 (21 negative; $1:$ P3 SL) \\
\hline 8 & 2011 & 15.7 & $3.5 \mathrm{mo}$ & 2 & 3.8 & Yes & $\begin{array}{c}6 \text { (4 negative; } 1: \mathrm{P} 1 \mathrm{SL} ; 1: \mathrm{P} 1 \mathrm{SL} \\
\text { and } \mathrm{P} 2 \mathrm{SL})\end{array}$ \\
\hline 9 & 2011 & 25.2 & $4 d$ & 2 & 3.3 & No & 6 (all negative) \\
\hline 9 & 2011 & 25.2 & $4 \mathrm{~d}$ & 1 & 1.6 & No & 6 (all negative) \\
\hline 10 & 2012 & 6.6 & $1.5 \mathrm{mo}$ & 2 & 2.3 & No & 0 \\
\hline 11 & 2012 & 11.4 & $2 w k$ & 2 & 1.5 & Yes & 6 (all negative) \\
\hline 12 & 2013 & 13.1 & 2 wk & 2 & 0.9 & No & 4 (3 negative; 1 : $\mathrm{P} 1 \mathrm{SL}$ ) \\
\hline 13 & 2014 & 10.0 & $2.1 \mathrm{mo}$ & 1 & 1.8 & Yes & 3 (all negative) \\
\hline 14 & 2014 & 9.0 & $3.3 \mathrm{mo}$ & 2 & 0.6 & Yes & 3 (all negative) \\
\hline
\end{tabular}


Table 3. Immunologic findings for 14 patients infected with iVDPV, Iran, 1995-2014*

\begin{tabular}{|c|c|c|c|c|c|c|c|c|c|c|}
\hline \multirow{2}{*}{$\begin{array}{l}\text { Patient } \\
\text { no. }\end{array}$} & \multirow{2}{*}{$\begin{array}{c}\text { Underlying } \\
\text { immunodeficiency }\end{array}$} & \multicolumn{6}{|c|}{ 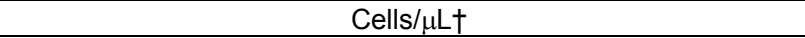 } & \multicolumn{3}{|c|}{ Concentration, mg/dLf } \\
\hline & & Leukocytes & ALC & CD3 & CD4 & CD8 & CD19 & $\lg G$ & $\lg M$ & $\lg A$ \\
\hline 1 & $\begin{array}{c}\text { Undefined } \\
\text { hypogammaglobulinemia }\end{array}$ & NA & NA & NA & NA & NA & NA & NA & NA & NA \\
\hline 2 & MHC2 & 6,300 & 3,642 & 1,216 & 608 & 607 & 1,460 & 200 & $<10$ & $<10$ \\
\hline 3 & SCID & 1,700 & 731 & 138 & 96 & 32 & 10 & 45 & $<10$ & $<10$ \\
\hline 4 & XLA & 6,500 & 3,375 & 2,700 & 1,404 & 1,290 & 35 & 556 & $<10$ & $<10$ \\
\hline 5 & SCID & 6,800 & 2,589 & 336 & 184 & 185 & 160 & $<10$ & $<10$ & $<10$ \\
\hline 6 & XLA & 8,500 & 4,000 & 2,760 & 1,920 & 835 & 40 & 20 & 58 & 25 \\
\hline 7 & NBS & 6,050 & 1,040 & 527 & 206 & 264 & 10 & 30 & 22 & $<10$ \\
\hline 8 & XLA & 9,400 & 4,470 & 4,201 & 2,547 & 1,564 & 10 & 80 & $<10$ & $<10$ \\
\hline 9 & SCID & 7,500 & 3,825 & 1,092 & 841 & 279 & 2,371 & $<10$ & 45 & $<10$ \\
\hline 10 & SCID & 7,200 & 2,174 & 652 & 543 & 163 & 1,413 & 40 & $<10$ & $<10$ \\
\hline 11 & Mu heavy chain & 14,400 & 10,080 & 8,769 & 4,636 & 4,132 & 110 & $600 \S$ & $<10$ & $<10$ \\
\hline 12 & NAT & NA & NA & NA & NA & NA & NA & NA & NA & NA \\
\hline 13 & XLA & 10,300 & 4,738 & 4,264 & 3,506 & 663 & 30 & 292 & $<10$ & $<10$ \\
\hline 14 & Agammaglobulinemia\# & 10,600 & 6,254 & 5,628 & 4,377 & 1,375 & 81 & 297 & 34 & 14 \\
\hline \multicolumn{11}{|c|}{ 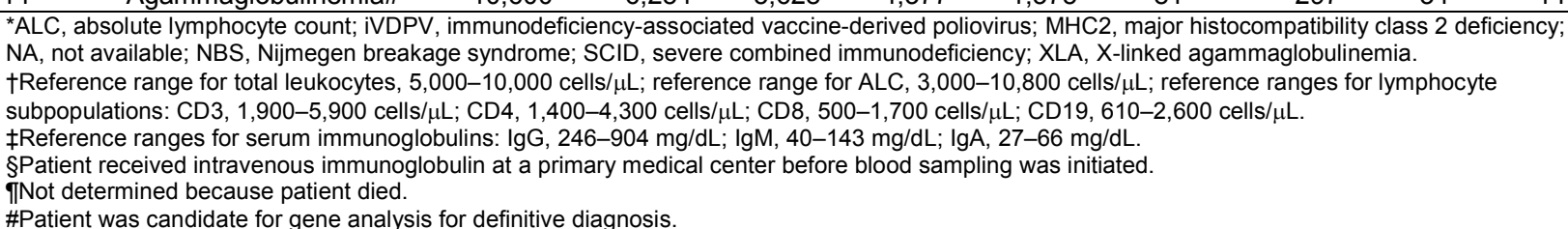 } \\
\hline
\end{tabular}

Shedding of iVDPV by patient 7 is also notable because he is one of the few case-patients with CID who eliminated the infection before death $(23,24)$. He had the longest period of iVDPV shedding among our patients before clearing the infection. His duration of virus shedding was several times longer than shedding durations in each of our patients with humoral immunodeficiencies. These observations appear to support the hypothesis of a probable role for cellular immunity in clearing enteroviral infections. Our patients were generally treated with monthly administration of IVIg. However, different IVIg preparations, doses, and settings in immunoglobulin replacement therapy might contribute to efficacy of treatment. Thereafter, to assess the independent role of immune status in clearance of infection, a comprehensive profile of potential confounding factors and therapeutic conditions, which might contribute to capability of virus clearance, is needed. This profile is missing in our study. Additional studies with comprehensive and appropriate adjustments for these factors are required to assess the immunologic response against enteroviral infections in patients with various types of primary immunodeficiencies.

A search for VDPV infection in contacts of our patients yielded negative results, and only Sabin-like polioviruses were isolated from few contacts, which indicates high vaccination coverage in Iran. Spread of iVDPVs to unimmunized contacts in the United States (6) and Morocco (25) showed potential risk for iVDPV transmission in populations with low immunity, which can lead to an outbreak. Maintaining high vaccination coverage reduces this risk.

The overall rate of accumulative nucleotide substitution in the genome of polioviruses is believed to be $\approx 1 \% /$ year $(6,26)$. Some investigators consider a range of $1 \%-2 \% /$ year as the overall rate of nucleotide variation in polioviruses $(27,28)$. Most of our VDPV isolates showed a divergence rate of $1 \%-2 \% / y e a r$. However, we observed unexpectedly high divergence rates beyond this range in some of our isolates. We propose 3 possible explanations for this difference.

First, for isolates with high divergence rates, the patient could have been infected with an already divergent virus, rather than the original vaccine strain. Thus, the virus had already replicated in a previous host before transmission to the patient. However, lack of any report of circulating VDPV from Iran does not support this explanation. High vaccination coverage and herd immunity against polioviruses in Iran would prevent any circulation of VDPVs. Negative results for VDPV screening in contacts of patients also does not support this explanation.

Second, it has been frequently observed that shortly after OPV administration, the initial rate of capsid region gene evolution is high in Sabin strains, which leads to VDPV emergence $(28,29)$. A high proportion of these changes are nonsynonymous substitutions in the genomic region, which codes for structural proteins. However, the synonymous mutations, mostly in nonstructural regions, occur at the expected rates. Changes in specific antigenic sites might increase additional nonsynonymous substitutions (29). These changes could be caused by effects of direct selection against attenuating mutations in the early stages of VDPV emergence. Selected mutations might carry unselected hitchhiker mutations in these early stages, which would contribute further to a higher initial evolution rate. After these initial selection events, VDPVs appear to evolve at rates closer to the unselected steady-state rate of $\approx 1 \%-2 \% /$ year. This alternative view is supported by only 
limited data from more prolonged infections because dates of initiation of most VDPV infections can only be estimated from clinical records but is consistent with available evidence (27).

Third, another explanation for higher rates of divergence in some of our isolates could be presence of mixed lineages or quasispecies of VDPVs in stool specimens from corresponding patients. This explanation is consistent with previous evidence, which indicated shedding of mixed-lineage VDPVs by patients with primary immunodeficiency $(27,28)$. Earlier detection of poliovirus shedding in our patients, possibly after exposure to OPV strains, could have provided precise information about timeline of VP1 divergence in our isolates. This detection could be another advantage of early screening for primary immunodeficiencies and VDPV shedding.

Eradication of wild-type poliovirus serotypes 2 and 3 indicates that eradication of all 3 serotypes can be expected in the near future. However, emergence of VDPVs still remains a threat to global eradication of poliomyelitis (2). A review of reports published by CDC showed that $\approx 100$ primary immunodeficiency patients with VDPV shedding have been documented $(1,4,18,19,30-32)$. By the end of 2014, Iran had reported the highest incidence of iVDPV infections (14 case-patients with AFP), followed by the United States (11 case-patients), and the United Kingdom, Egypt, and China (each with 6 case-patients). Similar to the United Kingdom and other industrialized countries, which reported few VAPP cases after switching to vaccination with IPV, only 3 cases occurred in the Unites States after OPV cessation in $2000(3,23,33)$. In contrast, the number of iVDPV cases reported from developing and middleincome countries has increased in recent years because of increased extended VDPV surveillance in these countries that used OPV $(18,34)$.

More than 20 outbreaks of circulating VDPV infection have been documented, mostly in countries with low OPV coverage (9). These outbreaks occurred while no cases of infection with iVDPV were reported from some of these countries, such as Nigeria, Democratic Republic of the Congo, Somalia, and Niger, where VDVPs have circulated for a long time $(4,9)$. To explain this observation, one should consider that patients with primary immunodeficiency do not have a chance for long survival in lowincome communities because of lack of proper supportive therapies $(35,36)$. Thus, even if they are infected with OPV strains, they may die of severe consequences of primary immunodeficiency before emergence of VDPV through prolonged enteral replication.

Environmental isolation of highly divergent VDPVs without an obvious source of shedding has been reported in different countries (37-39). In Finland, although only IPV vaccine has been administered since 1985 , neurovirulent and highly divergent VDPVs have been recurrently detected in sewage since 2008. Epidemiologic data and virologic characteristics suggest that these VDPVs might have originated from chronically infected patients with immunodeficiencies; however, the source of shedding remains to be identified (38). Such unidentified chronic shedding of VDPV might reintroduce neurovirulent viruses into the population and initiate outbreaks in the posteradication era if population immunity to poliovirus is not maintained.

High coverage of OPV vaccination disrupted wildtype poliovirus transmission in Iran in the late 20th century, and the last case of wild-type poliomyelitis was detected in 2000 through sensitive AFP surveillance (Figure). Iran has borders with 2 polio-endemic countries (Afghanistan and Pakistan), which necessitates maintaining high levels of serum and mucosal immunity in the population. Although no wild-type poliomyelitis case has been reported from Iran for many years, vaccine-associated paralysis occurs at a rate of a few cases every year and increases illnesses in immunodeficient patients.

Routine administration of trivalent OPV would inevitably lead to emergence of VDPVs and new VAPP cases. Conversely, vaccination with IPV might not stop virus transmission because of inefficient induction of mucosal immunity (40). However, vaccination with IPV might be too expensive for some low-income countries. Accordingly, the switch to a combination of bivalent OPV (serotypes 1 and 3) and IPV vaccination was implemented worldwide in April 2016 (2). We believe that immediate achievement of maximum immunization coverage is another vital point to be addressed in this strategy. Moreover, attempts to develop safer and more efficient poliovirus vaccines and polio antiviral drugs are warranted.

This study highlights the need for efficient iVDPV surveillance and the crucial role of patient registry.

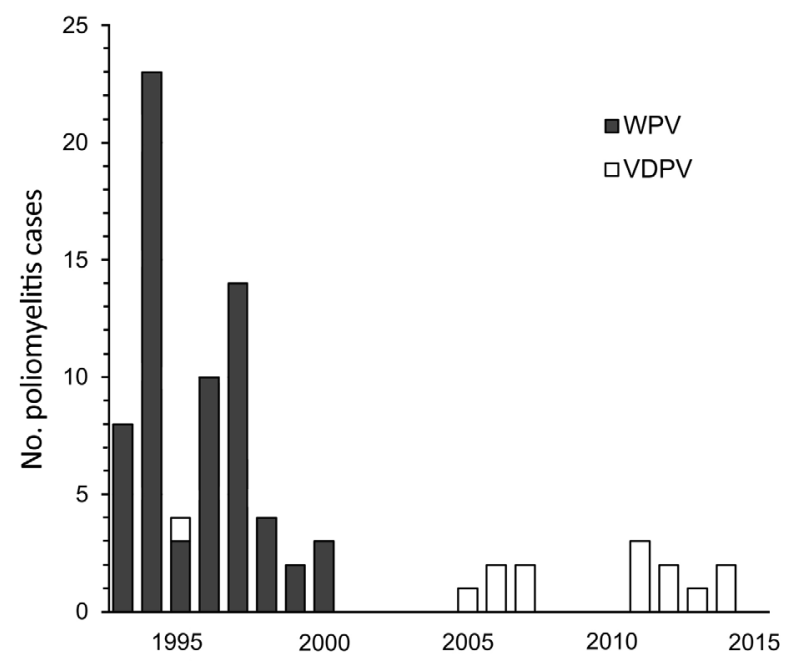

Figure. Poliomyelitis cases in Iran, 1995-2014. WPV, wild-type polioviruses; VDPV, vaccine-derived polioviruses. 
Vaccine-derived polioviruses not only endanger countries using OPV but also remain a threat to industrialized countries and the global polio eradication program. Regarding the association of immunodeficiency with this public health issue, we advocate establishment of sensitive clinical and laboratory surveillance to screen primary immunodeficiency patients for shedding of polioviruses.

Eradication might not be accomplished without robust registry and tracking capacities in every country to closely monitor the persistence of polioviruses in the environment and persons at high risk for infection. Achievement of this goal requires providing public health infrastructures, which is missing in some developing countries. In addition, global vigilance of final steps of the eradication program should be increased to attain maximum public contributions. Finally, worldwide IPV immunization should continue with high levels of coverage long after OPV cessation until reliable data indicate worldwide elimination of any poliovirus.

\section{Acknowledgments}

We thank Shabnam Abtahi and Amirafraz Fallah for providing assistance during the study.

This study was conducted at the National Polio Laboratory of Iran, Tehran, Iran, which is supported by the World Health Organization and Tehran University of Medical Sciences.

Dr. Shaghaghi is doctor of medicine and master of public health at the Tehran University of Medical Sciences, Tehran, Iran. His primary research interests are clinical and molecular studies of immunodeficiencies.

\section{References}

1. Diop OM, Burns CC, Sutter RW, Wassilak SG, Kew OM; Centers for Disease Control and Prevention (CDC). Update on vaccinederived polioviruses - worldwide, January 2014-March 2015. MMWR Morb Mortal Wkly Rep. 2015;64:640-6.

2. Morales M, Tangermann RH, Wassilak SG. Progress toward polio eradication-worldwide, 2015-2016. MMWR Morb Mortal Wkly Rep. 2016;65:470-3. http://dx.doi.org/10.15585/mmwr.mm6518a4

3. Trimble R, Atkins J, Quigg TC, Burns CC, Wallace GS, Thomas M, et al. Vaccine-associated paralytic poliomyelitis and BCG-osis in an immigrant child with severe combined immunodeficiency syndrome-Texas, 2013. MMWR Morb Mortal Wkly Rep. 2014;63:721-4.

4. Centers for Disease Control and Prevention. Update on vaccinederived polioviruses - worldwide, April 2011-June 2012. MMWR Morb Mortal Wkly Rep. 2012;61:741-6.

5. Minor PD, Macadam AJ, Stone DM, Almond JW. Genetic basis of attenuation of the Sabin oral poliovirus vaccines. Biologicals. 1993;21:357-63. http://dx.doi.org/10.1006/biol.1993.1096

6. Kew OM, Sutter RW, de Gourville EM, Dowdle WR, Pallansch MA. Vaccine-derived polioviruses and the endgame strategy for global polio eradication. Annu Rev Microbiol. 2005;59:587-635. http://dx.doi.org/10.1146/annurev.micro.58.030603.123625

7. Khetsuriani N, Prevots DR, Quick L, Elder ME, Pallansch M, Kew $\mathrm{O}$, et al. Persistence of vaccine-derived polioviruses among immunodeficient persons with vaccine-associated paralytic poliomyelitis. J Infect Dis. 2003;188:1845-52. http://dx.doi.org/10.1086/379791
8. Centers for Disease Control and Prevention. Laboratory surveillance for wild and vaccine-derived poliovirusesworldwide, January 2008-June 2009. MMWR Morb Mortal Wkly Rep. 2009;58:950-4.

9. Shaghaghi M, Parvaneh N, Ostad-Rahimi P, Fathi SM, Shahmahmoodi S, Abolhassani H, et al. Combined immunodeficiency presenting with vaccine-associated paralytic poliomyelitis: a case report and narrative review of literature. Immunol Invest. 2014;43:292-8. http://dx.doi.org/10.3109/088201 39.2013.859156

10. Shahmahmoodi S, Mamishi S, Aghamohammadi A, Aghazadeh N, Tabatabaie H, Gooya MM, et al. Vaccine-associated paralytic poliomyelitis in immunodeficient children, Iran, 1995-2008. Emerg Infect Dis. 2010;16:1133-6. http://dx.doi.org/10.3201/ eid1607.091606

11. Shahmahmoodi S, Parvaneh N, Burns C, Asghar H, Mamishi S, Tabatabaie $\mathrm{H}$, et al. Isolation of a type 3 vaccine-derived poliovirus (VDPV) from an Iranian child with X-linked agammaglobulinemia. Virus Res. 2008;137:168-72. http://dx.doi.org/10.1016/j.virusres.2008.07.006

12. Parvaneh N, Shahmahmoudi S, Tabatabai H, Zahraei M, Mousavi T, Esteghamati AR, et al. Vaccine-associated paralytic poliomyelitis in a patient with MHC class II deficiency. J Clin Virol. 2007;39:145-8. http://dx.doi.org/10.1016/j.jcv.2007.04.002

13. Mamishi S, Shahmahmoudi S, Tabatabaie H, Teimourian S, Pourakbari B, Gheisari Y, et al. Novel BTK mutation presenting with vaccine-associated paralytic poliomyelitis. Eur J Pediatr. 2008;167:1335-8. http://dx.doi.org/10.1007/s00431-008-0674-5

14. World Health Organization. Polio laboratory manual. 4th ed. WHO/IVB/04.10, 2004 [cited 2016 Jun 17]. http://apps.who. int/immunization_monitoring/laboratory_polio_resources/en/ index.html

15. Aghamohammadi A, Mohammadinejad P, Abolhassani H, Mirminachi B, Movahedi M, Gharagozlou M, et al. Primary immunodeficiency disorders in Iran: update and new insights from the third report of the national registry. J Clin Immunol. 2014;34:478-90. http://dx.doi.org/10.1007/s10875-014-0001-z

16. Rezaei N, Aghamohammadi A, Moin M, Pourpak Z, Movahedi M, Gharagozlou M, et al. Frequency and clinical manifestations of patients with primary immunodeficiency disorders in Iran: update from the Iranian Primary Immunodeficiency Registry. J Clin Immunol. 2006;26:519-32. http://dx.doi.org/10.1007/s10875-0069047-x

17. Buckley RH. Evaluation of suspected immunodeficiency. In: Behrman RE, Jenson HB, Stanton BF, editors. Nelson textbook of pediatrics. Philadelphia: Elsevier/Saunders; 2012. p. 715-22.

18. Diop OM, Burns CC, Wassilak SG, Kew OM; Centers for Disease Control and Prevention. Update on vaccine-derived poliovirusesworldwide, July 2012-December 2013. MMWR Morb Mortal Wkly Rep. 2014;63:242-8.

19. Centers for Disease Control and Prevention. Update on vaccinederived polioviruses-worldwide, January 2006-August 2007. MMWR Morb Mortal Wkly Rep. 2007;56:996-1001.

20. Racaniello VR, Ren R. Poliovirus biology and pathogenesis. Curr Top Microbiol Immunol. 1996;206:305-25. http://dx.doi.org/10.1007/978-3-642-85208-4_15

21. Al-Herz W, Moussa MA. Survival and predictors of death among primary immunodeficient patients: a registry-based study. J Clin Immunol. 2012;32:467-73. http://dx.doi.org/10.1007/ s10875-011-9636-1

22. Robbins FC. Polio. Rochester (NY): University of Rochester Press; 1999.

23. Alexander JP, Ehresmann K, Seward J, Wax G, Harriman K, Fuller S, et al. Transmission of imported vaccine-derived poliovirus in an undervaccinated community in Minnesota. J Infect Dis. 2009;199:391-7. http://dx.doi.org/10.1086/596052 
24. Driss N, Ben-Mustapha I, Mellouli F, Ben Yahia A, Touzi H, Bejaoui $\mathrm{M}$, et al. High susceptibility for enterovirus infection and virus excretion features in Tunisian patients with primary immunodeficiencies. Clin Vaccine Immunol. 2012;19:1684-9. http://dx.doi.org/10.1128/CVI.00293-12

25. Avellón A, Cabrerizo M, De Miguel T, Pérez-Breña P, Tenorio A, Pérez JL, et al. Paralysis case and contact spread of recombinant vaccine-derived poliovirus, Spain. Emerg Infect Dis. 2008;14:1807-9. http://dx.doi.org/10.3201/eid1411.080517

26. Gavrilin GV, Cherkasova EA, Lipskaya GY, Kew OM, Agol VI. Evolution of circulating wild poliovirus and of vaccine-derived poliovirus in an immunodeficient patient: a unifying model. J Virol. 2000;74:7381-90. http://dx.doi.org/10.1128/ JVI.74.16.7381-7390.2000

27. Odoom JK, Yunus Z, Dunn G, Minor PD, Martín J. Changes in population dynamics during long-term evolution of Sabin type 1 poliovirus in an immunodeficient patient. J Virol. 2008;82:917990. http://dx.doi.org/10.1128/JVI.00468-08

28. Martín J, Odoom K, Tuite G, Dunn G, Hopewell N, Cooper G, et al. Long-term excretion of vaccine-derived poliovirus by a healthy child. J Virol. 2004;78:13839-47. http://dx.doi.org/10.1128/ JVI.78.24.13839-13847.2004

29. van der Sanden S, Pallansch MA, Van De Kassteele J, El-Sayed N, Sutter RW, Koopmans M, et al. Shedding of vaccine viruses with increased antigenic and genetic divergence after vaccination of newborns with monovalent type 1 oral poliovirus vaccine. J Virol. 2009;83:8693-704. http://dx.doi.org/10.1128/ JVI.02388-08

30. Centers for Disease Control and Prevention. Update on vaccinederived polioviruses—worldwide, January 2008-June 2009. MMWR Morb Mortal Wkly Rep. 2009;58:1002-6.

31. Centers for Disease Control and Prevention. Update on vaccinederived polioviruses - worldwide, July 2009-March 2011. MMWR Morb Mortal Wkly Rep. 2011;60:846-50.

32. Centers for Disease Control and Prevention. Update on vaccine-derived polioviruses. MMWR Morb Mortal Wkly Rep. 2006;55:1093-7.

33. DeVries AS, Harper J, Murray A, Lexau C, Bahta L, Christensen J, et al. Vaccine-derived poliomyelitis 12 years after infection in Minnesota. N Engl J Med. 2011;364:2316-23. http://dx.doi.org/10.1056/NEJMoa1008677

34. Li L, Ivanova O, Driss N, Tiongco-Recto M, da Silva R, Shahmahmoodi S, et al. Poliovirus excretion among persons with primary immune deficiency disorders: summary of a seven-country study series. J Infect Dis. 2014;210(Suppl 1):S368-72. http://dx.doi.org/10.1093/infdis/jiu065

35. Halsey NA, Pinto J, Espinosa-Rosales F, Faure-Fontenla MA, da Silva E, Khan AJ, et al. Search for poliovirus carriers among people with primary immune deficiency diseases in the United States, Mexico, Brazil, and the United Kingdom. Bull World Health Organ. 2004;82:3-8.

36. de Silva R, Gunasena S, Ratnayake D, Wickremesinghe GD, Kumarasiri CD, Pushpakumara BA, et al. Prevalence of prolonged and chronic poliovirus excretion among persons with primary immune deficiency disorders in Sri Lanka. Vaccine. 2012;30:75615. http://dx.doi.org/10.1016/j.vaccine.2012.10.035

37. Blomqvist S, Savolainen C, Laine P, Hirttiö P, Lamminsalo E, Penttilä E, et al. Characterization of a highly evolved vaccinederived poliovirus type 3 isolated from sewage in Estonia. J Virol. 2004;78:4876-83. http://dx.doi.org/10.1128/JVI.78.9.48764883.2004

38. Roivainen M, Blomqvist S, Al-Hello H, Paananen A, Delpeyroux F, Kuusi M, et al. Highly divergent neurovirulent vaccine-derived polioviruses of all three serotypes are recurrently detected in Finnish sewage. Euro Surveill. 2010;15:pii: 19566.

39. Shulman LM, Manor Y, Handsher R, Delpeyroux F, McDonough MJ, Halmut T, et al. Molecular and antigenic characterization of a highly evolved derivative of the type 2 oral poliovaccine strain isolated from sewage in Israel. J Clin Microbiol. 2000;38:3729-34.

40. Sutter RW, Suleiman AJ, Malankar P, Al-Khusaiby S, Mehta F, Clements GB, et al. Trial of a supplemental dose of four poliovirus vaccines. N Engl J Med. 2000;343:767-73. http://dx.doi.org/10.1056/NEJM200009143431103

Address for correspondence: Asghar Aghamohammadi, Children's Medical Center Hospital, 62 Qarib St, Keshavarz Blvd, Tehran 14194, Iran; email: aghamohammadi@tums.ac.ir

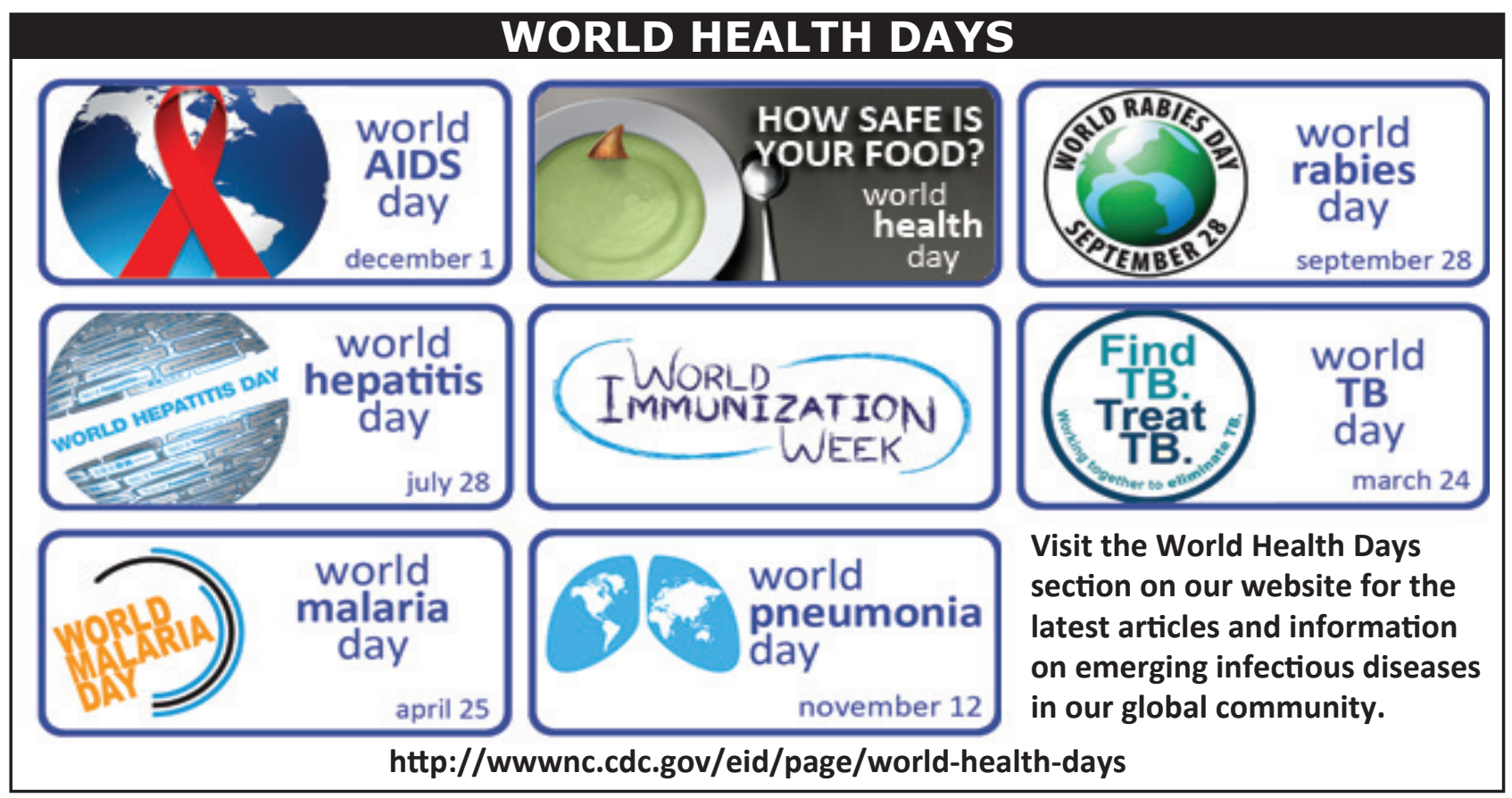

